EGU2020-5533

https://doi.org/10.5194/egusphere-egu2020-5533

EGU General Assembly 2020

(c) Author(s) 2022. This work is distributed under

the Creative Commons Attribution 4.0 License.

\title{
Numerical modelling of dynamic flood topographies in the Terai region, Nepal.
}

Maggie J. Creed ${ }^{1}$, Elizabeth H. Dingle ${ }^{2}$, Hugh D. Sinclair ${ }^{1}$, Dilip Gautam ${ }^{3}$, Noel Gourmelen ${ }^{1}$, Alistair G.L. Borthwick ${ }^{4}$, and Mikael Attal ${ }^{1}$

${ }^{1}$ School of Geosciences, University of Edinburgh, Edinburgh, UK (m.creed@ed.ac.uk)

${ }^{2}$ Department of Geography, Simon Fraser University, Burnaby, BC, Canada

${ }^{3}$ Practical Action Consulting, Kathmandu, Nepal

${ }^{4}$ School of Engineering, University of Edinburgh, Edinburgh, UK

Rivers sourced from the Himalayas support $\sim 10 \%$ of the global population living on the IndoGangetic Plain. These rivers can be a source of devastating floods. Flood hazard maps used to inform early warnings systems in the Terai region in southern Nepal are based on static, outdated DEMs, which may not reflect the current river and floodplain topography. Sediment dynamics can change the river course and the distribution of flow down large bifurcation nodes, affecting flood inundation extent. These processes are rarely considered in flood prediction models for this region. In this study, using a 2D depth-averaged hydrodynamic model, several flood scenarios for the Karnali River are investigated, including different DEMs, variable bed elevations, and a scenario with bed levels modified at an important bifurcation node to reflect field observations. Inundation extent varied by upto $14 \%$ between scenarios for a 1-in-20 year flood discharge. Our results suggest that combining regular field measurements of bed elevation, with updated DEMs, could help to improve future flood prediction maps. Updating model input parameters is particularly important following large flood events and/or large landslides in the upstream catchment, which could increase bed aggradation and provoke channel switching in highly mobile, alluvial river systems. 